\title{
One-pot Solvent-free Catalytic Dimerization Reaction of Phenylacetylene to 1-Phenylnaphthalene
}

\author{
AVAT (ARMAN) TAHERPOUR ${ }^{\mathrm{a}, \mathrm{b}, *}$, SEPEHR TABAN $^{\mathrm{c}}$ and AKO YARI ${ }^{\mathrm{a}}$ \\ ${ }^{a}$ Department of Organic Chemistry, Faculty of Chemistry, Razi University, P.O. Box: 67149-67346, \\ Kermanshah, Iran \\ ${ }^{b}$ Medical Biology Research Center, Kermanshah University of Medical Sciences, Kermanshah, Iran \\ ${ }^{\mathrm{c} C h e m i s t r y ~ D e p a r t m e n t, ~ S c i e n c e ~ F a c u l t y, ~ I s l a m i c ~ A z a d ~ U n i v e r s i t y, ~ A r a k ~ B r a n c h, ~ P . O . ~ B o x ~ 38135-567, ~}$ \\ Arak, Iran \\ e-mail: avatarman.taherpour@gmail.com
}

MS received 21 September 2014; revised 28 April 2015; accepted 29 April 2015

\begin{abstract}
In this study, we report a smooth one-pot, solvent-free catalytic dimerization of phenylacetylene (1) to 1-phenylnaphthalene $(2)$ by $\mathrm{Cu} / \mathrm{C}$ at room temperature in good yield $(\sim 100 \%)$. In the computational study, the structure of the 1-phenylnaphthalene was optimized by DFT-B3LYP/6-31G* method. The rotation barrier around C-C of the phenyl and naphthalene parts of the molecule and its UV-Visible spectrum were calculated. The modelling of the mechanism of production of $\mathbf{2}$ from $\mathbf{1}$ was performed with and without $\mathrm{Cu} / \mathrm{C}$ catalyst. The data of EDS and SEM of the $\mathrm{Cu} / \mathrm{C}$ catalyst surface are also reported.
\end{abstract}

Keywords. Catalytic reactions; Phenylacetylene; 1-Phenylnaphthalene; Copper(0)-Carbone catalyst; Solvent free synthesis; EDS; SEM; Molecular modelling.

\section{Introduction}

Polycyclic aromatic hydrocarbons (PAHs) have been attracting a lot of attention in recent years. ${ }^{1-6}$ They are formed as a result of burning organic compounds and in natural thermal geological reactions. PAHs occur in oil, coal, and tar deposits, and are produced as by-products of fuel burning (fossil fuel or biomass). ${ }^{1-3}$ PAHs are found primarily in soil, sediment and oily substances, as opposed to water or air. ${ }^{4} 1$-phenylnaphthalene was prepared by the reaction of $\alpha$-halonaphthalenes with mercury diphenyl, ${ }^{7 \mathrm{a}, \mathrm{b}}$ or with benzene in the presence of aluminum chloride, ${ }^{7 a, b}$ and by means of a Grignard synthesis, starting with either bromobenzene, or cyclohexyl chloride and $\alpha$-tetralone, ${ }^{7 \mathrm{a}, \mathrm{c}, \mathrm{d}}$ or with $\alpha$-bromonaphthalene and cyclohexanone. ${ }^{7 \text { a,c-e }}$ A $60 \%$ yield is reported for the Grignard preparation from cyclohexanone. ${ }^{7 \mathrm{a}, \mathrm{g}}$ The formation of the hydrocarbon through the diazo reaction, ${ }^{7 \mathrm{a}, \mathrm{g}-\mathrm{j}}$ appears to be less attractive than the described method. Dehydrogenation of the reduced naphthalene is accomplished by the use of sulfur, ${ }^{7 a, c}$ bromine, ${ }^{7 a, e}$ platinum black, or selenium. ${ }^{7 \mathrm{a}, \mathrm{b}} 1$ Phenylnaphthalene has also been prepared by oxidation of 1-Phenyldialin. ${ }^{7 \mathrm{a}}$

\footnotetext{
*For correspondence
}

An efficient organocatalytic method for constructing biaryls through aromatic $\mathrm{C}-\mathrm{H}$ activation is reported by Sun et al. in 2010. ${ }^{8}$ They have described the identification of a cross-coupling between aryl iodides/bromides and the $\mathrm{C}-\mathrm{H}$ bonds of arenes that is mediated solely by the presence of 1,10-phenanthroline as catalyst in the presence of $\mathrm{KO} t-\mathrm{Bu}$ as a base. This apparently transition metal-free process provides a new strategy to achieve direct $\mathrm{C}-\mathrm{H}$ functionalization. ${ }^{8}$

In 2011, the dimerization reaction of phenylacetylene (1) in presence of $\mathrm{Pd}(0)$ nanoparticles was reported by Firuzabadi et al. ${ }^{9}$ In this reaction 1,4-diphenyl-but1-en-3-yne was produced. It is demonstrated in that report that the nanoparticles show high catalytic activity for the Sonogashira-Hagihara coupling reaction of various aryl halides as well as heteroaryl halides and also $\beta$-bromo styrene with phenylacetylene under copper-, ligand- and amine-free conditions. ${ }^{9-14}$ It is also reported that the reactions were carried out at $100^{\circ} \mathrm{C}$ in molten tetrabutylammonium bromide (TBAB) or polyethylene glycol in the presence of potassium acetate as a base in argon atmosphere. Dimerization of phenylacetylene in similar conditions in air was also previously described by Firuzabadi et al. ${ }^{9}$

The dimerization of arylethynes catalyzed by vanadium phthalocyanine to give substituted biaryls have been previously investigated. ${ }^{15}$ In 2009, the dimerization 


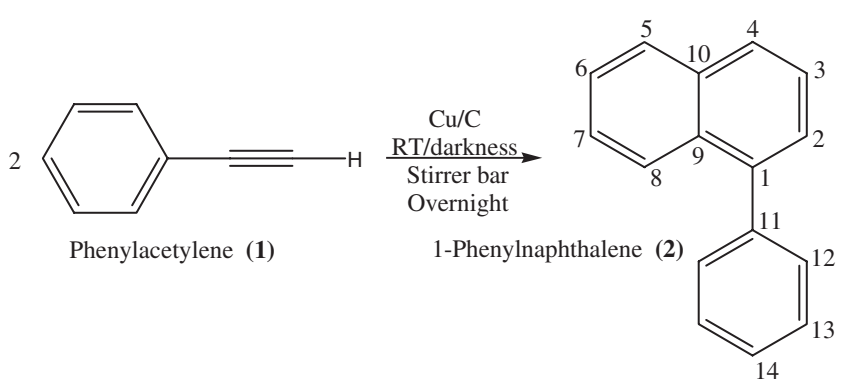

Figure 1. One-pot, solvent-free catalytic dimerization of phenylacetylene (1) to 1-phenylnaphthalene (2) by $\mathrm{Cu} / \mathrm{C}$ at room temperature.

reaction of para-Cl-phenylacethylene in presence of vanadium phthalocyanine was reported by Cicero et al. ${ }^{15}$ The reaction had produced the chloro substituted of 1-phenylnaphthalene. The reaction yield was always high, and for many examples, it was only slightly affected by the aryl substituent. It is reported that this is related to results obtained with metalloporphyrins, which give lower selectivity due to the presence of variable amounts of triphenylbenzenes (figure 1). ${ }^{15}$

Herein, we report a smooth one-pot, solvent-free catalytic dimerization of phenylacetylene $\mathbf{1}(\mathrm{H}-\mathrm{C} \equiv \mathrm{C}-\mathrm{Ph})$ to 1-phenylnaphthalene 2 by $\mathrm{Cu} / \mathrm{C}$ in darkness and at room temperature in good yield $(\sim 100 \%)$. The computational method employed covers density functional theory (DFT) approaches. The structure of $\mathbf{2}$ was optimized by DFT-B3LYP/6-31G* method. The barrier rotation around $\mathrm{C}-\mathrm{C}$ of the phenyl and naphthalene parts of the molecule and its UV-Visible spectrum were calculated by B3LYP/6-31G* method. The modelling of the mechanism of formation of 1-phenylnaphthalene from phenylacetylene was performed with and without $\mathrm{Cu} / \mathrm{C}$ catalyst. In this study, the data of EDS and SEM of the $\mathrm{Cu} / \mathrm{C}$ catalyst surface are reported as well.

\section{Experimental}

\subsection{Materials, methods and instruments}

The synthesized 1-phenylnaphthalene $\mathbf{2}$ is a known compound (with CAS\# 605-02-7) and its physical data, infrared and ${ }^{1} \mathrm{H}-\mathrm{NMR}$ spectra are essentially identical with that of authentic sample. ${ }^{16}$ The FT-IR spectra were recorded on a Shimadzu FT-IR 8000 spectrometer. ${ }^{1} \mathrm{H}-\mathrm{NMR}$ and ${ }^{13} \mathrm{C}$-NMR spectra were determined on a $300 \mathrm{MHz}$ Brüker spectrometer. The solvent for NMR recording was $\mathrm{CDCl}_{3}$. The product was examined by GC-MS (figures S1 and S2 in Supplementary Information). GC and GC-MS analysis were performed on a Shimadzu QP5050A GCMS instrument, injector at $200^{\circ} \mathrm{C}$; temperature program: $100^{\circ} \mathrm{C}(2 \mathrm{~min})$, then $16^{\circ} \mathrm{C}$

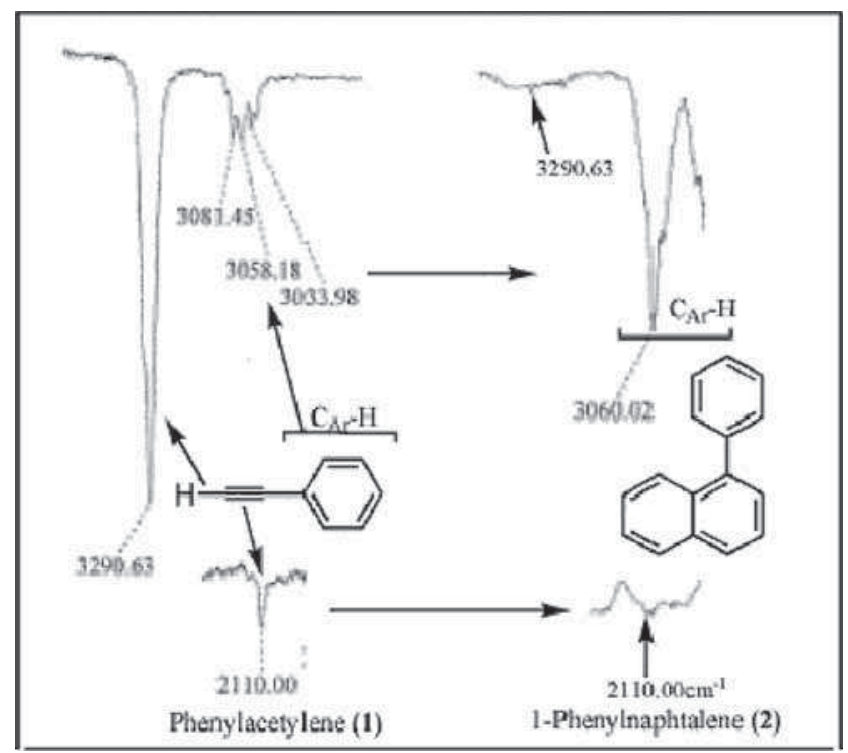

Figure 2. Comparison of FT-IR spectra of phenylacetylene (1) and 1-phenylnapthalene (2). The peaks at 3291 and 2110 $\mathrm{cm}^{-1}$ have disappeared in spectrum of $\mathbf{2}$.

per min till $250^{\circ} \mathrm{C}$ on a Zebron capillary column ZB-5 (0.25 $\mu \mathrm{m}$ thickness, $0.32 \mathrm{~mm}$ diameter, $30 \mathrm{~m}$ length). TLC experiment with $\mathrm{CHCl}_{3}$-petroleum ether-acetone (1:1:1) on silica gel plate showed just one strong spot for $\mathbf{2}$ in comparison with the starting material $\mathbf{1}$. No details are given about the by-products and only the final product was considered.

\subsection{Procedures}

2.2a Synthesis of 1-Phenylnaphthalene (2): A mixture of phenylacetylene (1) ( $2 \mathrm{~mL}, 1.86 \mathrm{~g}, 0.018 \mathrm{~mol})$ and the catalyst $\mathrm{Cu} / \mathrm{C}(0.1 \mathrm{mg})$ was made in a dried tube with a small magnetic stirrer bar. The tube was sealed and then stirred overnight (about $12 \mathrm{~h}$ ) at room temperature and in darkness. A yellowish oily liquid was afforded after filtration and separation of the catalyst. The product $\mathbf{2}$ was identified by the analytical data and comparing with the authentic sample data. ${ }^{16}$ The workup and GC yields were about $\sim 100 \%$ (2 $\mathrm{mL}, 1.85 \mathrm{~g}, 0.009 \mathrm{~mol}$ ). See figures 2, S1 and S2 (S1 and $\mathrm{S} 2$ are in supplementary information.). B.p.: $322-$ $324^{\circ} \mathrm{C}$ (lit. B.p. $\left.=324-325^{\circ} \mathrm{C}\right) .{ }^{16}$ FT-IR $\left(\mathrm{KBr}, \mathrm{cm}^{-1}\right)$ : 3000-3060(C-H; Ar.), 1812-2000(H-C; Ar. ring), 1594, 1487, 1443(C=C; Ar. ring), 780, 754 and 702 $\mathrm{cm}^{-1}$ (OOP of C-H; Ar. ring). ${ }^{1} \mathrm{H}-\mathrm{NMR} \delta_{H}\left(\mathrm{CDCl}_{3}\right)$ : 7.87-7.91(m, H8), 7.83-7.85(m, H2), 7.51-7.53(m, $\mathrm{H} 5), 7.48-7.50(\mathrm{~m}, \mathrm{H} 4), 7.47(\mathrm{~d}, \mathrm{H} 12,6 \mathrm{~Hz}), 7.45-$ 7.47(dd, H3, 6Hz), 7.42(m, H7), 7.40(m, H6), 7.347.36(t, H13, 6Hz) and 7.30-7.32(d, H14, 6Hz). ${ }^{13} \mathrm{C}-$ NMR: 132.5(C11), 131.4(C1), 130.1(C10), 128.4(C9), 128.2(C13), 128.0(C8), 127.6(C5), 126.9(C4), 126.2(C14), 
126.1(C12), 126.0(C7), 125.4(C6), 125.3(C2) and 125.2(C3). MS: $\mathrm{m} / \mathrm{z}$ (relative intensity), $\mathrm{MW}=204 ; 204$ $\left(\mathrm{M}^{+}, 94.9\right), 203(100), 202(60.5), 189(2.3), 176(4.5)$, 126(2.2), 102(8.1), 101(53.5), 88(18.6) and 76(10.5). Molecular formula is $\mathrm{C}_{16} \mathrm{H}_{12}$.

\subsection{Molecular Modeling}

The calculations on the structure of 1-phenylnaphthalene $\mathbf{2}$ were performed by appropriate quantum mechanical method. In this study, the employed computational method covers density functional theory (DFT) approaches. The structure of $\mathbf{2}$ was optimized by DFT-B3LYP/6-31G* method. All of the calculations have been performed by Spartan ' 10 package that was implemented on a HP-Proliant-DL180G6(12 cores) Server. ${ }^{17}$ The graphing operation for barrier rotation $\left(\phi_{10,1,11,16}\right)$ around $\mathrm{C} 1-\mathrm{C} 11$ in $\mathbf{2}$ was performed using the Microsoft Office Excel-2013 program.

Figures 3 to 9 and table 1 show the appropriate model, operations and selected structural data. To calculate the barrier rotation around the $\mathrm{C}-\mathrm{C}$ bond in 1-phenylnaphthalene (on $\mathrm{Cu} / \mathrm{C}$ catalyst) the appropriate dihedral angle change $\left(\phi_{10,1,11,16}\right)$ around the $\mathrm{C} 1$ C11 bond was utilized and optimized in each step. The Hartree energy was converted to $\mathrm{kcal}^{\mathrm{mol}} \mathrm{m}^{-1}$ and relative energies were calculated. The graph in figure 4 demonstrates the appropriate data. The optimized structures of 1-phenylnaphthalene, transition states and intermediate (with and without $\mathrm{Cu} / \mathrm{C}$ catalyst pathways) were carried out by DFT-B3LYP/6-31G* method.

Figure 3 demonstrates the selected structural data of 2 in ground state $\left(\phi_{10,1,11,16}=90.52^{\circ}\right)$ and the barrier
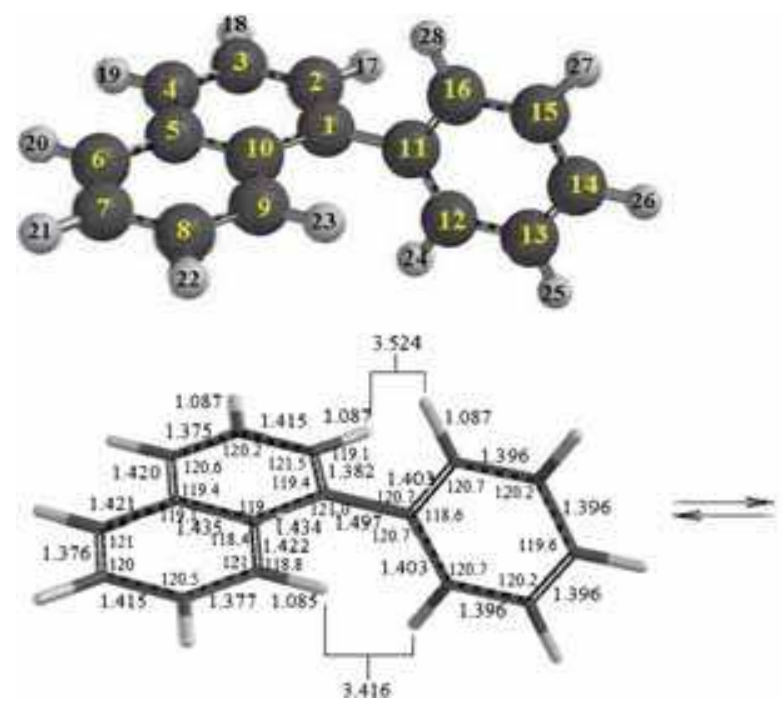

form $\left(\phi_{10,1,11,16}=0^{\circ}\right)$. The steric restraint and the strains in the barrier form have made some changes in bond lengths and bond angles as compared to the ground state form. By increasing the steric restraint and the strains in the barrier form, the bond length of $\mathrm{C} 1-\mathrm{C} 11, \mathrm{H} 23$ $\mathrm{H} 24$ and H17-H24 were changed from 1.497, 3.416 and $3.524 \AA$ (in ground state) to $1.523,0.899$ and $1.787 \AA$ (in barrier form), respectively. Likewise, by increasing the steric restraint and the strains in the barrier form, the bond angles of $\mathrm{C} 2 \mathrm{C} 1 \mathrm{C} 10, \mathrm{C} 10 \mathrm{C} 1 \mathrm{C} 11, \mathrm{C} 1 \mathrm{C} 11 \mathrm{C} 12$ and C12C11C16 were changed from 119.4, 121.0, 120.7 and $118.0^{\circ}$ (in ground state) to $118.2,123.1,122.1$ and 116.8 (in barrier form), respectively. The barrier energy for bond rotation around $\phi_{10,1,11,16}$ was calculated 52.92 $\mathrm{kcal} \mathrm{mol}^{-1}$ by B3LYP/6-31G* method (figure 4).

Figure 5(a) shows the calculated UV/Visible spectra for 2 . The calculated $\lambda_{\max }$ in vacuum by DFT-B3LYP/ 6-31G* method was achieved $269.2 \mathrm{~nm}$ (lit $\lambda_{\max }=$ $285 \mathrm{~nm}$ in n-hexane). The energies of the boundary MOs (HOMO and LUMO) of $\mathbf{2}$ are shown in Figure 5(b). The HOMO, LUMO and $\Delta E_{\text {HOMO-LUMO }}$ were calculated as: $-5.73,-0.96$ and $4.77 \mathrm{eV}$, respectively.

Figure 6 demonstrates the predicted mechanism of reaction between two moles of phenyl-acetylene to produce 1-Phenylnaphthalene 2 . The transition states $\left(\mathrm{TS}_{1}\right.$ and $\left.\mathrm{TS}_{2}\right)$ and also the intermediate for a $[1,5] \mathrm{H}$ shift are shown in figure 6. The hydrogen atom 19 has migrated from $\mathrm{C} 10$ to $\mathrm{C} 4$ by a $[1,5] \mathrm{H}$-shift (sigma tropic) reaction. Table 1 shows the selected structural data of the structures during the production of $\mathbf{2}$ calculated by B3LYP/6-31G* method. The bond lengths and distances between the selected atoms $\mathrm{C} 1-\mathrm{C} 2, \mathrm{C} 2-\mathrm{C} 3$, C3-C4, C4-C5, C5-C10, C1-C10, C1-C11, C10-H19, H17-H18 and H18-H19 are: 1.295, 2.419, 1.277, 1.430,
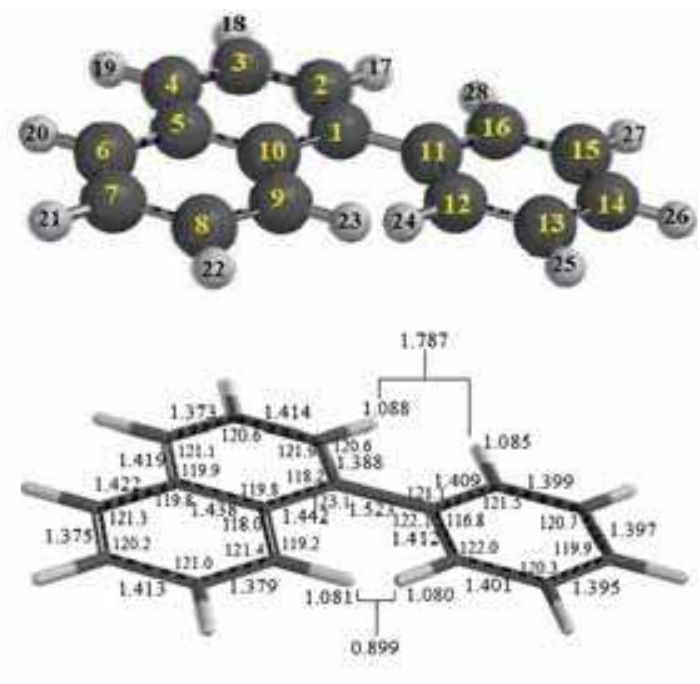

Figure 3. The selected structural data of 1-Phenylnaphthalene (2) in ground state $\left(\Phi_{10,1,11,16}=90.52^{\circ}\right)$ and the barrier form $\left(\Phi_{10,1,11,16}=0^{\circ}\right)$. 
Table 1. Selected structural data of the transition states $\left[\mathrm{TS}_{1}\right],\left[\mathrm{TS}_{2}\right]$ and the intermediate compound [In.].

\begin{tabular}{lccc}
\hline & \multicolumn{3}{c}{$\left[\mathrm{TS}_{1}\right] \&\left[\mathrm{TS}_{2}\right]$ and [In. } \\
\cline { 2 - 4 } Selected data & {$\left[\mathrm{TS}_{1}\right]$} & {$[\mathrm{In}]$.} & {$\left[\mathrm{TS}_{2}\right]$} \\
\hline & & & \\
Bond length( ${ }^{\mathrm{A}}$ ) & & & \\
C1-C2 & 1.295 & 1.372 & 1.368 \\
C2-C3 & 2.419 & 1.444 & 1.432 \\
C3-C4 & 1.277 & 1.359 & 1.408 \\
C4-C5 & 1.430 & 1.356 & 1.418 \\
C5-C6 & 1.403 & 1.428 & 1.432 \\
C5-C10 & 1.404 & 1.564 & 1.520 \\
C9-C10 & 1.389 & 1.489 & 1.499 \\
C1-C10 & 2.802 & 1.504 & 1.502 \\
C1-C11 & 1.426 & 1.482 & 1.480 \\
C2-H17 & 1.071 & 1.088 & 1.090 \\
C3-H18 & 1.074 & 1.091 & 1.095 \\
C10-H19 & 1.082 & 1.115 & 1.457 \\
H17-H18 & 3.114 & 2.527 & 2.419 \\
H18-H19 & 4.352 & 4.472 & 2.585 \\
& & & \\
Bond angle $\left(^{\circ}\right)$ & & & \\
C1C2C3 & 126.92 & 119.56 & 122.01 \\
C2C3C4 & 76.27 & 119.73 & 127.24 \\
C3C4C5 & 170.12 & 124.41 & 116.13 \\
C4C5C6 & 124.08 & 129.34 & 118.76 \\
C4C5C10 & 116.64 & 117.52 & 125.45 \\
C2C1C10 & 103.78 & 119.77 & 117.35 \\
C2C1C11 & 159.81 & 120.60 & 121.68 \\
C10C1C11 & 96.39 & 119.55 & 120.88 \\
C5C10C1 & 78.62 & 115.12 & 116.31 \\
C5C10H19 & 122.10 & 91.69 & 71.79 \\
C1C10H19 & 92.98 & 102.56 & 90.25 \\
C1C2H17 & 144.51 & 119.13 & 118.52 \\
C4C3H18 & 154.25 & 121.78 & 118.42 \\
& & & \\
Torsional angle $\left({ }^{\circ}\right)$ & & & \\
C1C2C3C4 & 27.39 & -24.28 & 3.80 \\
C2C3C4C5 & -17.79 & 14.26 & 1.88 \\
C3C4C5C6 & 120.51 & -174.76 & 169.37 \\
C3C2C1C10 & -3.97 & 17.97 & 0.16 \\
C3C4C5C10 & -55.29 & 1.15 & -11.72 \\
C4C5C10H19 & -19.01 & -111.58 & -65.84 \\
C2C1C10C5 & -42.17 & -2.92 & -8.58 \\
C2C1C10H19 & 79.99 & 95.00 & 61.32 \\
H17C2C3H18 & 34.19 & -21.98 & 1.03 \\
C5C10C1C11 & 138.66 & -179.52 & 174.76 \\
\hline & & & \\
\hline
\end{tabular}

$1.404,2.802,1.426,1.082,3.114$ and $4.352 \AA$, respectively. For the intermediate [In.], the bond lengths and distances between the selected atoms C10-H19, C1C10, C5-C10 and C1-C11 are: 1.115, 1.504, 1.564 and 1.482 , respectively. In table 1 are shown, as well as $\left[\mathrm{TS}_{1}\right]$ and [In.] the selected bond lengths and distances $\mathrm{C} 10-\mathrm{H} 19, \mathrm{C} 1-\mathrm{C} 10, \mathrm{C} 5-\mathrm{C} 10$ and $\mathrm{C} 1-\mathrm{C} 11$ for $\left[\mathrm{TS}_{2}\right.$ ]: $1.457,1.502,1.520$ and $1.480 \AA$, respectively. The calculated energy levels of the [In.] and $\left[\mathrm{TS}_{2}\right]$ by B3LYP/6-31G* method, are: 8.09 and $27.13 \mathrm{kcal}$ $\mathrm{mol}^{-1}$, respectively, less stable than the precursor. The calculated energy level of the product $\mathbf{2}$ is about $98 \mathrm{kcal}$ $\mathrm{mol}^{-1}$ more stable than the precursor 1 (figure 7).

Figure 7 shows the graph of the reaction between two moles of $\mathbf{1}$ to produce one mole $\mathbf{2}$ with and without $\mathrm{Cu} / \mathrm{C}$ catalyst. With respect to the results, the first step of this reaction was slow and rate determining. The activation energy of the first step was calculated to be about $107.42 \mathrm{kcal} \mathrm{mol}^{-1}$ without $\mathrm{Cu} / \mathrm{C}$ catalyst. This activation energy for the first step and with $\mathrm{Cu} / \mathrm{C}$ catalyst was about $66.66 \mathrm{kcal} \mathrm{mol}^{-1}$ by B3LYP/6-31G* method. The results show that the activation energy of this stage (by utilizing $\mathrm{Cu} / \mathrm{C}$ catalyst pathway) decreases by about 41 $\mathrm{kcal} \mathrm{mol}{ }^{-1}$. The results demonstrate that the slow and first step of this reaction was affected by the adsorption of phenylacetylene and the $\left[\mathrm{TS}_{1}\right]$ on $\mathrm{Cu} / \mathrm{C}$ catalyst surface. An imaginary structure of $\mathrm{Cu}$ surface was constructed and optimized by B3LYP/6-31G* method, to construct a model for adsorbing two molecules of $\mathbf{1}$ and their $\left[\mathrm{TS}_{1}\right]$ on $\mathrm{Cu} / \mathrm{C}$ catalyst surface. This model of $\mathrm{Cu}$ surface includes $64 \mathrm{Cu}$ atoms $(8 \mathrm{x} 8)$ with $24.60 \AA$ diagonal and $17.84 \AA$ A length. The optimized Cu-surface shows a curvature across its diagonal. Figure 8 shows the model of Cu-catalyst surface by B3LYP/6-31G* method: (a) Ball and spoke model, b) Electron density model, c) Electrostatic potential model with natural charges and d) Mulliken Charge map. The calculated results demonstrate that the Mulliken and natural charges have not been homogenized on the selected $\mathrm{Cu}$-surface. The natural charge map of the optimized $\mathrm{Cu}$-surface is shown in figure $4(\mathrm{C})$; the natural charges were changed from +0.055 to -0.048 esu. The most positive places are shown by blue color in figure 4(C) with +0.055 to +0.040 esu. It seems that these positions are better locations to adsorb the electron density distribution (EDD) of the first step transition state $\left(\mathrm{TS}_{1}\right)$ among the selected $\mathrm{Cu}$-surface. So, these positions were chosen for modelling of this stage with $\mathrm{Cu}-$ catalyst with the phenylacetylene molecules. Figure 9 (a and b) presents the model of interaction between $\left[\mathrm{TS}_{1}\right]$ and the $\mathrm{Cu}$-catalyst surface ((a) Space filling and (b) ball and spoke models). In this figure, we can obviously see the changes about the $\mathrm{Cu}$ atom positions of the $\mathrm{Cu}$-model catalyst due to adsorption of the $\left[\mathrm{TS}_{1}\right]$. As mentioned above the calculated results by the modelling show that the activation energy of this stage (by utilizing $\mathrm{Cu} / \mathrm{C}$ catalyst pathway) to decrease by about $41 \mathrm{kcal} \mathrm{mol}^{-1}$.

\subsection{EDS and SEM Results}

Figure S3 (in SI) shows the EDS results. This figure shows the copper atoms in the $\mathrm{Cu} / \mathrm{C}$ catalyst. The 


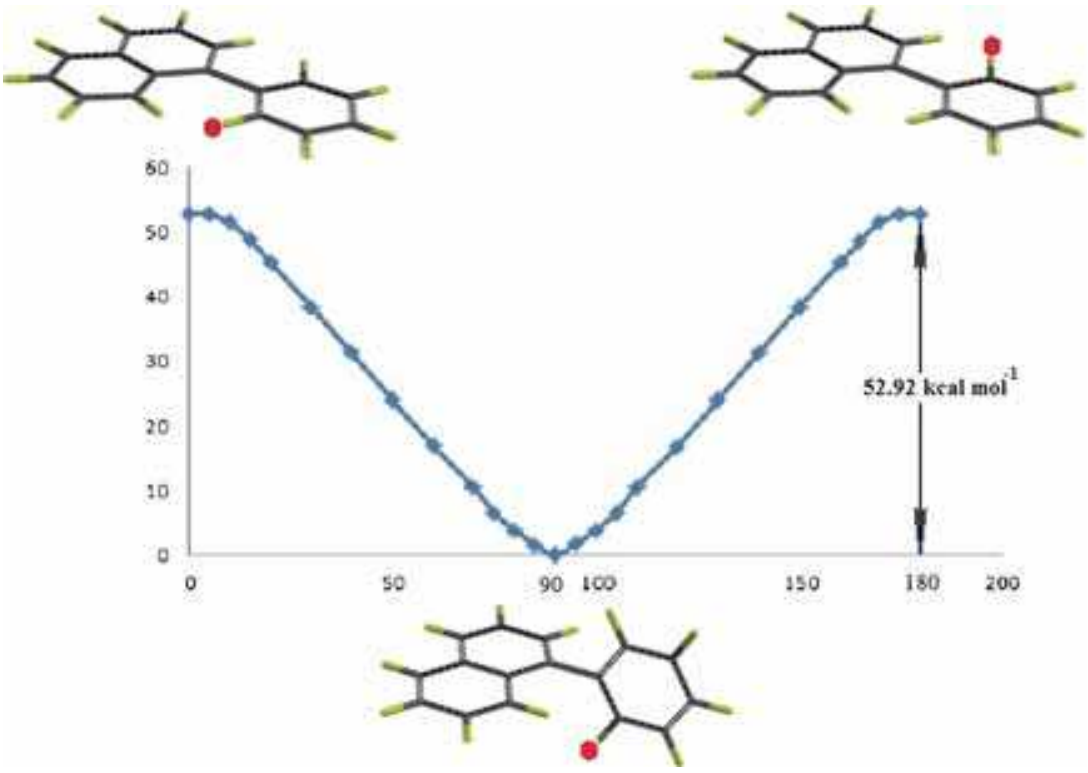

Figure 4. The rotation process in 1-phenylnaphthalene (2) in ground state $\left(\Phi_{10,1,11,16}=90.52^{\circ}\right)$ and the barrier form $\left(\Phi_{10,1,11,16}=0^{\circ}\right)$.

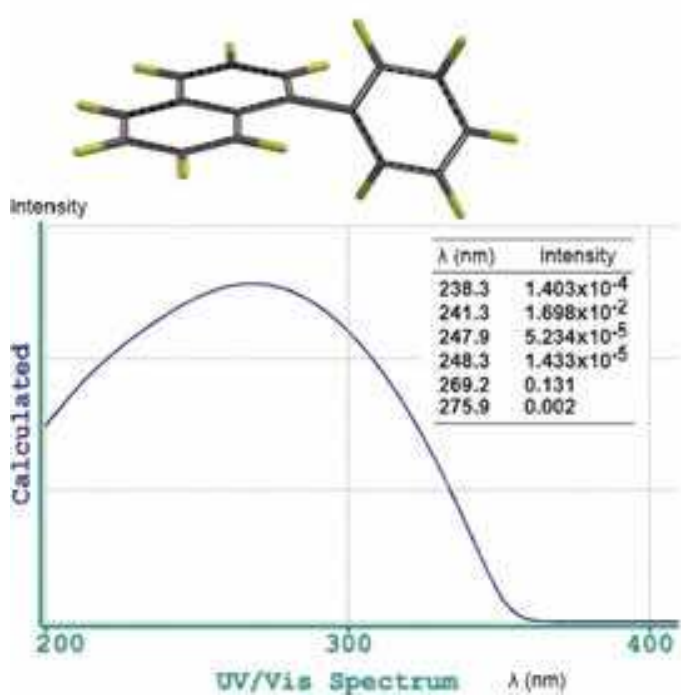

(a)

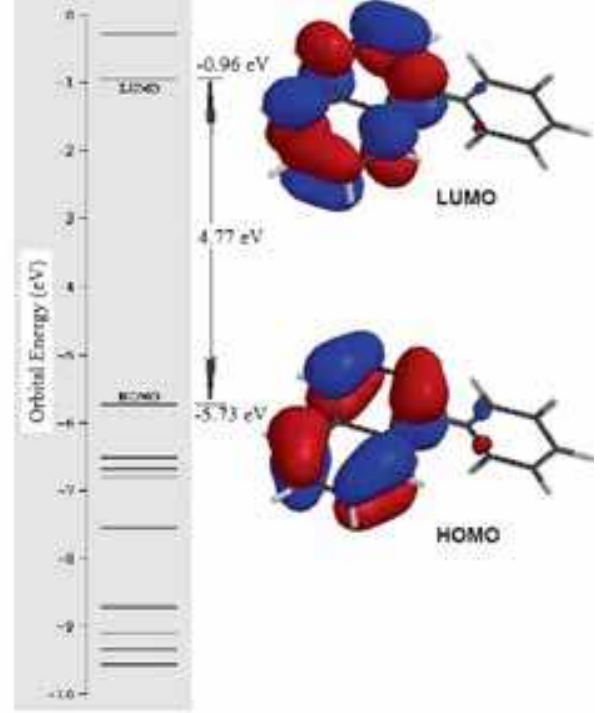

(b)

Figure 5. (a) The calculated UV/Visible spectrum for 1-phenylnaphthalene (2). Calculated $\lambda_{\max }=269.2 \mathrm{~nm}$ in vacuum by DFT-B3LYP/6-31G* $\operatorname{method}$ (lit. $\lambda_{\max }=285 \mathrm{~nm}$ in nhexane).

(b) The energies of MOs (HOMO and LUMO) of 1-phenylnaphthalene (2).
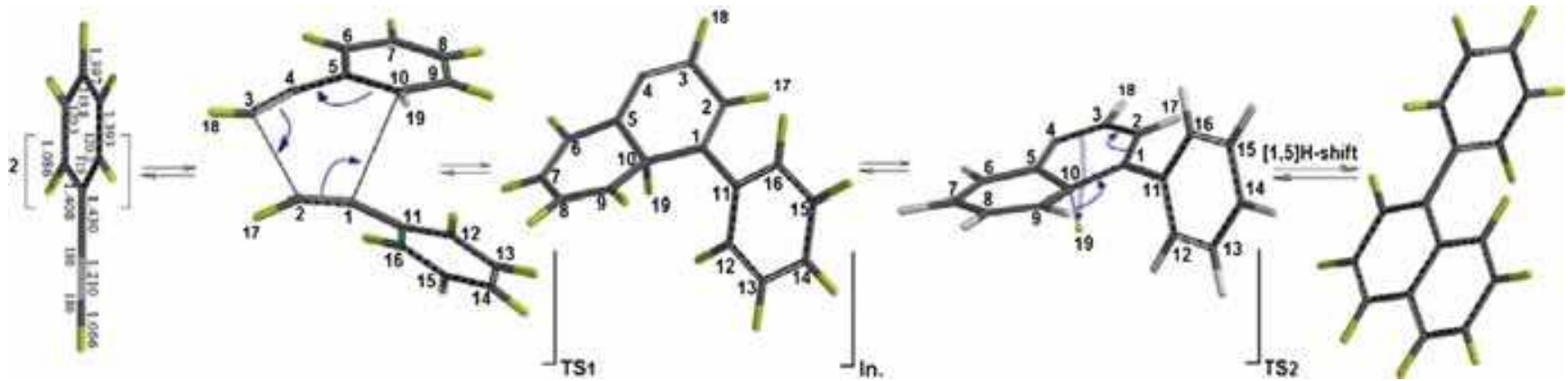

Figure 6. The predicted mechanism of reaction between two moles of phenylacetylene (1) to produce one mole of 1phenylnaphthalene (2). 


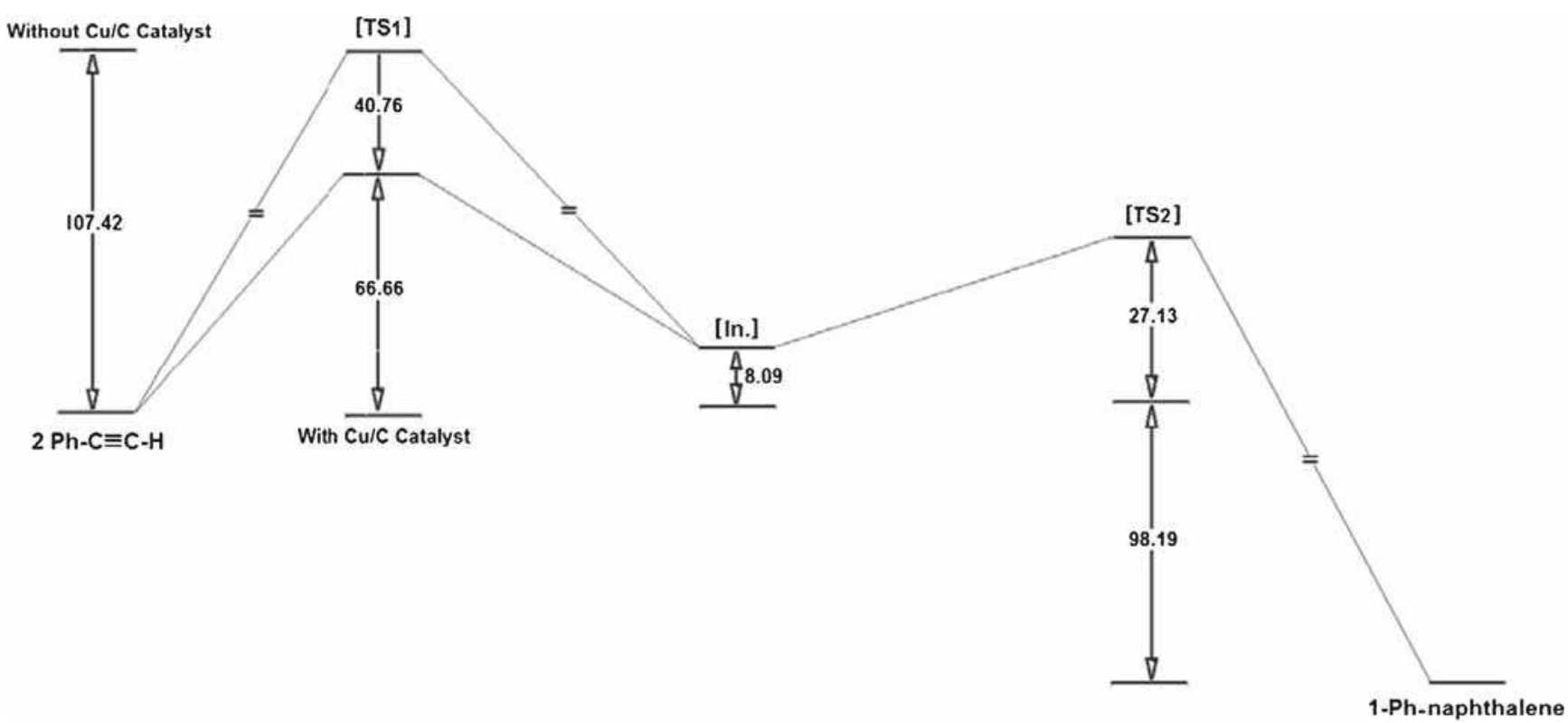

Figure 7. The graph of the reaction of two moles of phenylacetylene to produce 1-Ppenylnaphthalene (2) with and without catalyst $\mathrm{Cu} / \mathrm{C}$. With catalyst, the activation energy of the first step was calculated to be about $41 \mathrm{kcal} \mathrm{mol}^{-1}$ less than without $\mathrm{Cu} / \mathrm{C}$ catalyst.

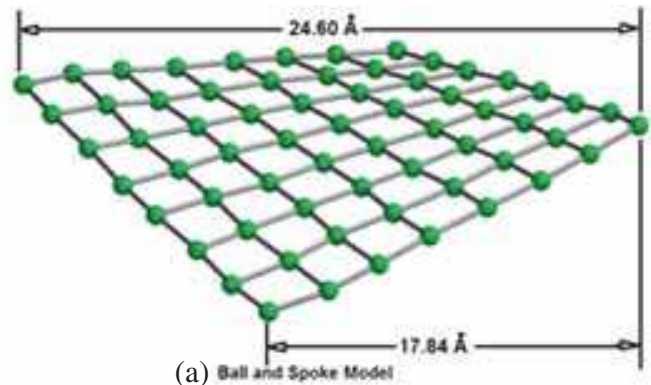

(a) Gall and spoke teodes

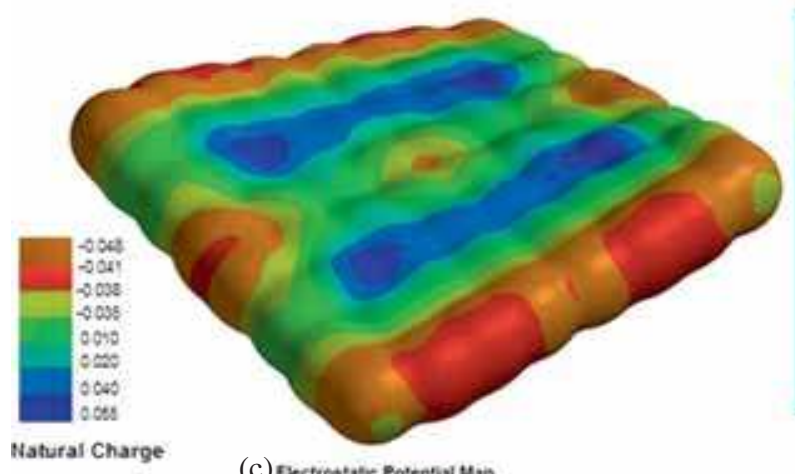

(c) Eiectrostate potential thap

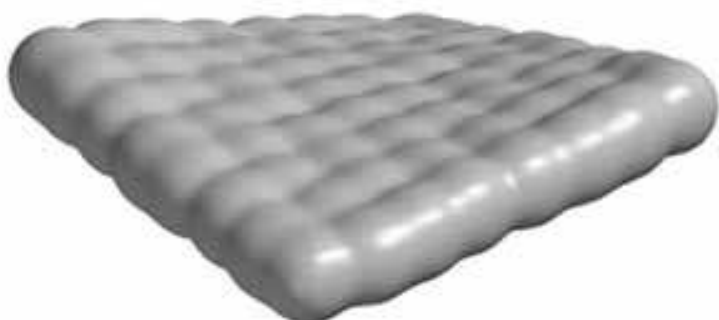

(b) Electrin Densaty

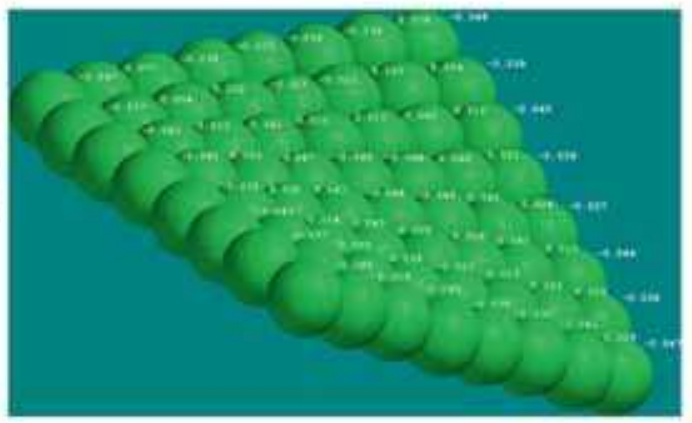

(d) Hakes Charge Map

Figure 8. The calculated model of Cu-catalyst surface by B3LYP/6-31G* method. a) Ball and spoke model, b) Electron density model, c) Electrostatic potential model with natural charges and d) Mulliken Charge map.

results of electron microscopy image of the copperimpregnated carbon $(\mathrm{Cu} / \mathrm{C})$ sample with shows that the structure of the SEM image $(100 \mu \mathrm{m})$ of free copper consisting of homogenous and porous structure of $\mathrm{Cu} / \mathrm{C}$ catalyst. Figures $10, \mathrm{~S} 3$ and $\mathrm{S} 4$ show the SEM images of copper-impregnated carbon $(\mathrm{Cu} / \mathrm{C})$ catalyst. The SEM images show the establishment and adhesion capability of chemical and physical characteristics and mechanics of the porous surface of copper metal particles (figure 11). 


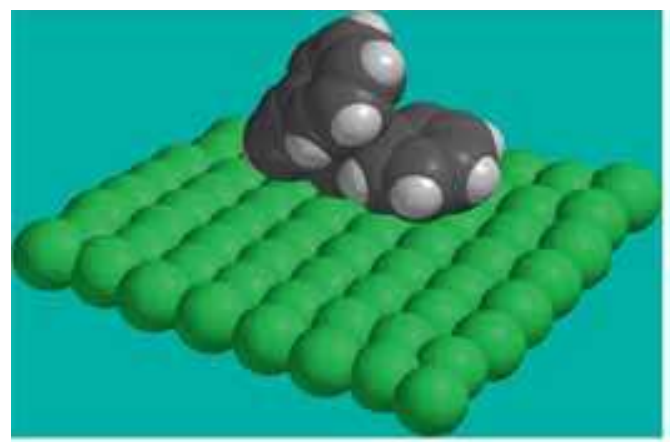

(a) Space filing model of [TS1] on the catalyst Cuic

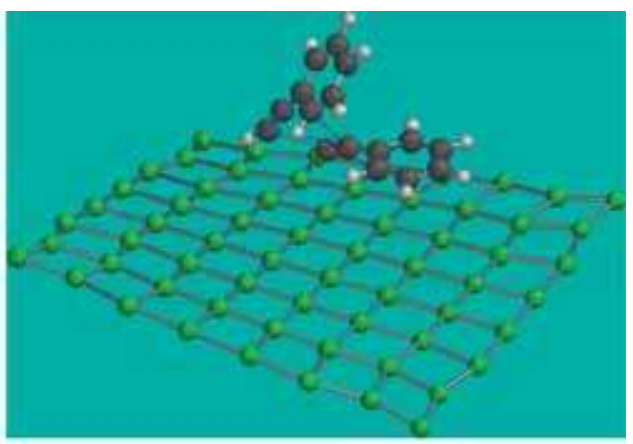

(b) Ball and Spoke model of [TS1] on the catalyst Cu/C

Figure 9. The model of interaction between $\left[\mathbf{T S}_{\mathbf{1}}\right]$ and the $\mathrm{Cu}$-catalyst surface. (a) Space filling and (b) ball and spoke models.

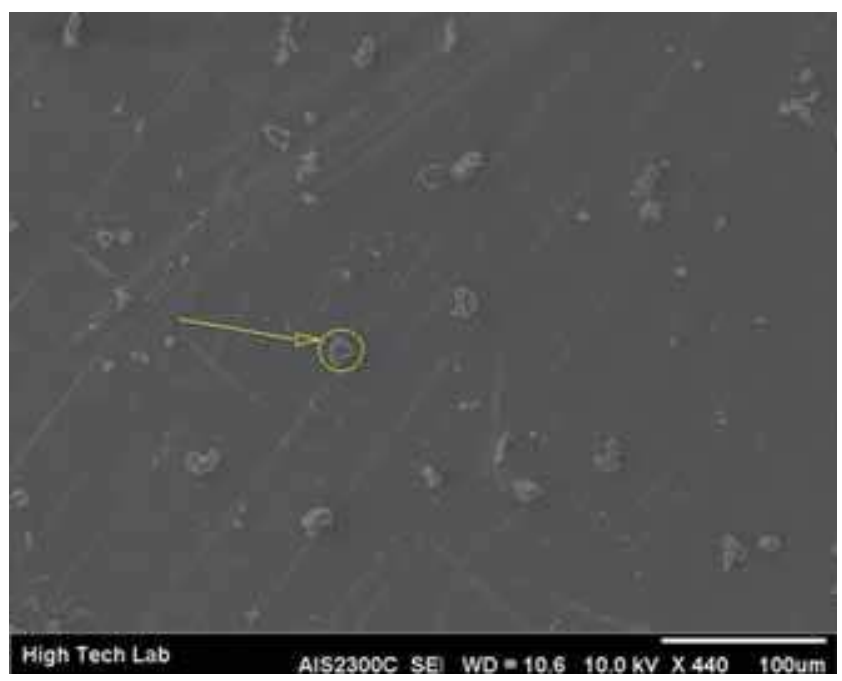

Figure 10. SEM image of copper-impregnated Carbon $(\mathrm{Cu} / \mathrm{C})$ catalyst in scale of $100 \mu \mathrm{m}$.

\section{Results and Discussion}

The reaction was carried out as a one-pot, solventfree catalytic dimerization of phenylacetylene 1 to 1 phenylnaphthalene 2 by $\mathrm{Cu} / \mathrm{C}$ at room temperature and in good yield $(\sim 100 \%)$. The comparison of the structural and spectral data of $\mathbf{1}$ and the identified compound $\mathbf{2}$ shows complete conversion of $\mathbf{1}$ to $\mathbf{2}$ under the reaction conditions. There was no additional compound in the reaction vessel. The reactant vessel was under a dark cover during the time of reaction (overnight). So, the reaction was not under photochemical conditions.

The FT-IR spectrum of $\mathbf{1}$ has two important peaks at 2110 and $3291 \mathrm{~cm}^{-1}$ for stretching vibrational frequencies of $-\mathrm{C} \equiv \mathrm{C}-$ and $\equiv \mathrm{C}-\mathrm{H}$, respectively. These two signals disappeared in the FT-IR of the product 2 . The FTIR of the product just shows the aromatic signals (figure 2). The ${ }^{1} \mathrm{H}-\mathrm{NMR}$ spectrum of phenylacetylene showed a

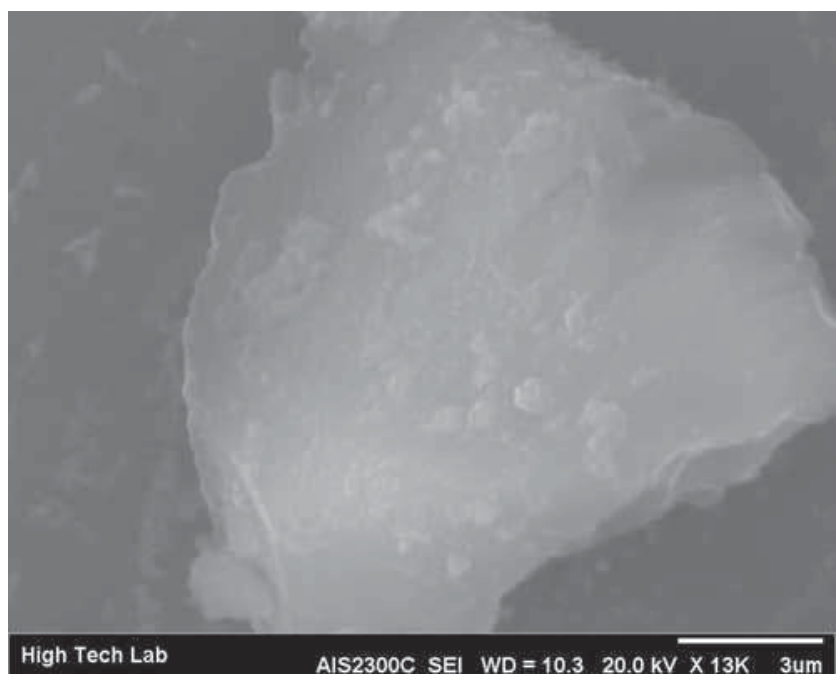

Figure 11. SEM image of copper-impregnated Carbon $(\mathrm{Cu} / \mathrm{C})$ catalyst in scale of $10 \mu \mathrm{m}$. See Figure 10.

signal at chemical shift $\delta=2.16 \mathrm{ppm}$ for acetylenic $\mathrm{H}$ atom. This signal disappeared completely in the ${ }^{1} \mathrm{H}-\mathrm{NMR}$ spectrum of product 2 . The ${ }^{1} \mathrm{H}-\mathrm{NMR}$ spectrum of 2 shows the NOE enhancement for H8 (perihydrogen) as doublet-multiplet by $\mathrm{H} 7$ and phenyl substituted group on $\mathrm{C} 1$ (figure $\mathrm{S} 1$ in supplementary information). The ${ }^{13} \mathrm{C}$-NMR spectrum of $\mathbf{2}$ showed fourteen signals in accordance with its structure. A GC-Mass experiment was carried out on product 2 . The GC yield of the experiment was about $\sim 100 \%$. The mass spectrum of 2 showed the molecular weight $[\mathrm{M}]^{+}$. signal at $\mathrm{m} / \mathrm{z}=204$. The signal of $[\mathrm{M}]^{+\cdot / 2}$ appeared at 102 and a signal at 101 for $\left[\left([\mathrm{M}]^{+\cdot / 2}\right)\right.$-1] (figure $\mathrm{S} 2$ in supplementary information). The boiling point of the product was measured by Emrich's method. ${ }^{15}$ The boiling point of 2 was $322-324^{\circ} \mathrm{C}$ (lit. B.p. $=324-325^{\circ} \mathrm{C}$ ). ${ }^{14}$ These results confirm conversion of $\mathbf{1}$ to $\mathbf{2}$ under the mentioned conditions. 


\section{Conclusions}

A smooth one-pot, solvent-free catalytic dimerization of phenylacetylene to 1-phenylnaphthalene by $\mathrm{Cu} / \mathrm{C}$ in darkness at room temperature in good yield $(\sim 100 \%)$ is reported. The identification of the product was carried out by the physical data, FT-IR, ${ }^{1} \mathrm{H}-\mathrm{NMR},{ }^{13} \mathrm{C}$ NMR and mass spectra and compared with the authentic sample data. The structure of 1-phenylnaphthalene was optimized by DFT-B3LYP/6-31G* method. The barrier rotation around $\mathrm{C}-\mathrm{C}$ of the phenyl and naphthalene parts of 1-phenylnaphthalene $\left(52.92 \mathrm{kcal} \mathrm{mol}^{-1}\right)$ and its UV-Visible spectrum $\left(\lambda_{\max }=269.2 \mathrm{~nm}\right)$ were calculated by B3LYP/6-31G* method. The modelling of the production mechanism of 1-phenylnaphthalene from phenylacetylene was performed with and without $\mathrm{Cu} / \mathrm{C}$ catalyst. The calculated results by the modelling showed that the activation energy (by utilizing $\mathrm{Cu} / \mathrm{C}$ catalyst) decreases by about $41 \mathrm{kcal} \mathrm{mol}^{-1}$. In this study, the data of EDS and SEM of the $\mathrm{Cu} / \mathrm{C}$ catalyst surface are reported as well.

\section{Supplementary Information}

${ }^{1} \mathrm{H}-\mathrm{NMR}$ spectra of phenyl-acetylene, 1-phenylnaphthalene (figures S1 and S2), EDS analysis (figure S3) and the SEM of $\mathrm{Cu} / \mathrm{C}$ catalyst (figure S4) are shown in the Supplementary Information which is available at www.ias.ac.in/chemsci.

\section{Acknowledgements}

A T gratefully acknowledges the colleagues in Chemistry Department of The University of QueenslandAustralia for their useful suggestions. The authors are grateful to the Research and Computational Lab of Theoretical Chemistry and Nano Structures of Razi University Kermanshah-Iran for supporting this study.

\section{References}

1. Fetzer J C 2000 Polycycl. Aromat. Comp. 27143

2. Herwig P T, Enkelmann V, Schmelz O and Müllen K 2000 Chem. Eur. J. 61834
3. Glenn R M 1995 In Activated carbon applications in the food and pharmaceutical industries (Boca Raton FL: CRC Press) p. 125

4. Portella G, Poater J and Solà M 2005 J. Phys. Org. Chem. 18785

5. Luch A 2005 In The Carcinogenic Effects of Polycyclic Aromatic Hydrocarbons (London: Imperial College)

6. Hawley G G 1997 In Condensed Chemical Dictionary $13^{\text {th }}$ Ed. (New York: Van Nostrand Reinhold Company Inc.)

7. (a) Weiss R 1955 Org. Syntheses 3 729; (b) Chattaway F D 1893 J. Chem. Soc. 63 1187; (c) Weiss R and Woidich K 1925 Monatsh. Chem. 46 455; (d) Cook J W and Lawrence C A 1936 J. Chem. Soc. 11 1431; (e) Vesely V and Stursa F 1933 Collect. Czech. Chem. Commun. 5 344; (f) Orchin M and Reggel L 1947 J. Am. Chem. Soc. 69 505; (g) Grieve W S M and Hay D H 1938 J. Chem. Soc. 13 108; (h) Waters W H 1939 J. Chem. Soc. 14 864; (i) Hodgson H H and Marsden E $1940 \mathrm{~J}$. Chem. Soc. 15 208; (j) Bachmann W E and Hofmann R A 1944 Org. Reac. 2248

8. Sun C L, Li H, Yu D G, Yu M, Zhou X, Lu X Y, Huang K, Zheng S F, Li B J and Shi Z J 2010 Nature Chem. 2 1044

9. Firouzabadi H, Iranpoor $\mathrm{N}$ and Ghaderi A 2011 Org. Biomol. Chem. 9865

10. Sonogashira K, Tohda Y and Hagihara N 1975 Tetrahedron Lett. 164467

11. Chinchilla R and Najera C 2007 Chem. Rev. 107 874

12. Gil-Molto J and Najera C 2006 Adv. Synth. Catal. 348 1874

13. Dudnik A and Gevorgyan V 2010 Angew. Chem. Int. Ed. 492096

14. Cicero D, Lembo A, Leoni A and Tagliatesta P 2009 New J. Chem. 332162

15. Vogel A 1986 In Vogel's Textbook of Practical Organic Chemistry. Including qualitative organic analysis $\left(4^{\text {th }}\right.$ Ed). (England: Longman Group Limited)

16. (a) Pouchert C L 1983 In The Aldrich Library of NMR Spectra (2 ${ }^{\text {th }}$ Ed.). (Milwaukee, Wisconsin: Aldrich Chemical Company Inc.) 1 pp. 2, 7402, 762; (b) Pouchert C L 1981 In The Aldrich Library of Inferared Spectra $3^{\text {th }}$ Ed. (Milwaukee, Wisconsin: Aldrich Chemical Company Inc.) pp. 27, 40-2, 578; (c) 1-phenylnaphthalene http://www. chemsynthesis.com/base/chemical-structure-5127.html

17. Spatran '10-Quantum Mechanics Program: (PC/x86) 1.1 .0 v4. 2011 (Irvine CA: Wavefunction Inc.) 